\title{
Optimizing the Personalized, Risk-Adjusted Management of Pulmonary Embolism: An Integrated Clinical Trial Programme
}

\author{
Stefano Barco ${ }^{1}$ Stavros V. Konstantinides ${ }^{1}$ \\ ${ }^{1}$ Center for Thrombosis and Hemostasis, University Medical Center of \\ the Johannes Gutenberg University-Mainz, Mainz, Germany \\ Hämostaseologie 2019;39:117-127. \\ Address for correspondence Stavros V. Konstantinides, MD, Center \\ for Thrombosis and Hemostasis, University Medical Center Mainz, \\ Langenbeckstrasse 1, Building 403, 55131 Mainz, Germany \\ (e-mail: stavros.konstantinides@unimedizin-mainz.de).
}

\section{Abstract}

Keywords

- pulmonary embolism

- risk stratification

- clinical trials

- anticoagulation

- systemic thrombolysis

Zusammenfassung
Acute pulmonary embolism (PE) contributes significantly to the global burden of cardiovascular disease. The severity of the acute PE event determines the expected estimated risk of early death. This risk is influenced by the degree of dysfunction of the right ventricle (RV), as assessed by the presence of acute RV pressure overload on imaging and/or elevated cardiac biomarkers, and by demographic and clinical factors, including relevant comorbidities. Haemodynamic instability and cardiogenic shock is at the top of the PE severity spectrum, as it represents the most extreme manifestation of RV failure and a key determinant of poor prognosis. Ideally, risk-adjusted treatment should implement: (1) optimized timing and regimens of reperfusion therapy for unstable patients; (2) early discharge and continuation of anticoagulation treatment at home (low-risk PE); or (3) hospital admission and clinical/haemodynamic monitoring in patients at intermediate risk. The challenge is now to provide the basis for a comprehensive personalized, risk-adjusted care for patients with acute PE. The aim of the integrated academic clinical trial programme of the Center for Thrombosis and Hemostasis at the University of Mainz is to develop and prospectively validate, in multinational studies, strategies for reperfusion and anticoagulant treatment of acute $\mathrm{PE}$ across the entire spectrum of early risk as well as clinical pathways for post-PE patient care and follow-up.

Akute Lungenembolie (PE) trägt signifikant zur globalen Belastung von Herz-KreislaufErkrankungen bei. Die Schwere des akuten PE-Ereignisses bestimmt das erwartete geschätzte Risiko eines frühen Todes. Dieses Risiko wird durch den Grad der Dysfunktion des rechten Ventrikels (RV) beeinflusst, der durch die akute RV-Drucküberlastung auf Bildgebung und / oder erhöhte kardiale Biomarker sowie durch demographische und klinische Faktoren, einschließlich relevanter Komorbiditäten, beurteilt wird. Die hämodynamische Instabilität und der kardiogene Schock stehen an der Spitze des PESchweregrads, da sie die extremste Manifestation des RV-Versagens darstellen und eine Schlüsseldeterminante für eine schlechte Prognose darstellen. Im Idealfall sollte eine risikoadjustierte Behandlung Folgendes umfassen: (1) optimiertes Timing und Regime der Reperfusionstherapie für instabile Patienten; (2) frühzeitige Entlassung und Fortsetzung der Antikoagulationsbehandlung zu Hause (Low-Risk-PE); oder (3) received

July 4, 2018

accepted after revision

August 14, 2018 (c) 2019 Georg Thieme Verlag KG Stuttgart . New York
DOI https://doi.org/

10.1055/s-0038-1673413. ISSN 0720-9355.

Augst 14,2018 
Schlüsselwörter

- Lungenembolie

- Risikostratifizierung

- klinische Studien

- Antikoagulation

- systemische

Thrombolyse
Krankenhausaufnahme und klinisches / hämodynamisches Monitoring bei Patienten mit mittlerem Risiko. Die Herausforderung besteht nun darin, die Basis für eine umfassende personalisierte, risikoadjustierte Versorgung von Patienten mit akutem PE zu schaffen. Ziel des integrierten akademischen klinischen Studienprogramms des Zentrums für Thrombose und Hämostase an der Universität Mainz ist es, in multinationalen Studien Strategien zur Reperfusion und Antikoagulansbehandlung akuter PE auch über das gesamte Frührisiko hinweg zu entwickeln und prospektiv zu validieren als klinische Pfade für Post-PE-Patientenversorgung und Follow-up.

\section{Acute Pulmonary Embolism: Contribution of the CTH to the Evolving Concept of Risk-Adapted Management}

Acute pulmonary embolism (PE) is a significant contributor to the global burden of cardiovascular disease. ${ }^{1}$ In Europe, the number of deaths related to venous thromboembolism (VTE) was estimated to be as high as 370,000 per year, corresponding to approximately $12 \%$ of all annual deaths. ${ }^{2}$ This also means that, when the fatalities primarily due to cancer are excluded, acute PE represents the main direct cause of mortality within the first few weeks following VTE diagnosis. ${ }^{3,4}$

Apart from the impact on the health and well-being of the population, the direct and indirect costs related to PE and/or deep vein thrombosis are substantial and show a steadily increasing trend in aging populations throughout the world, particularly in Europe and North America. ${ }^{5-7}$ Economic analyses also highlight in this context the high potential for cost savings in the future, which can be achieved through the improvement of VTE preventive measures, the implementation of evidence-based risk-adjusted management algorithms and the better, timely identification of long-term sequelae of acute PE.

The severity of the acute PE event determines the expected (estimated) risk of early death. This risk is influenced by:

- The degree of dysfunction of the right ventricle (RV), as assessed by the presence of acute RV pressure overload on imaging (echocardiography or computed tomography pulmonary angiography [CTPA]) and/or elevated cardiac biomarkers (cardiac troponins or natriuretic peptides) in the circulation.

- Demographic and clinical factors, including relevant comorbidities, which have been identified, standardized and validated in clinical prediction rules and scores. ${ }^{8,9}$

Haemodynamic instability and cardiogenic shock is at the top of the PE severity spectrum, as it represents the most extreme manifestation of RV dysfunction/failure and a key determinant of poor prognosis. ${ }^{10}$ In fact, whereas 30-day mortality rates are as low as $0.5 \%$ in haemodynamically stable, 'low-risk' patients, they can be higher than $20 \%$ in patients with haemodynamic collapse. ${ }^{11}$ This group of unstable patients (less than $5 \%$ of all patients diagnosed with $\mathrm{PE}$ ) represents the only accepted indication for the systemic thrombolytic or other reperfusion therapy to prevent early death. ${ }^{1}$ On the other hand, for the vast majority of normotensive PE patients with acute $\mathrm{PE}$, anticoagulation remains the primary treatment option. ${ }^{1,12}$ According to current guidelines of the European Society of Cardiology (ESC), these patients should further be stratified into an intermediate and low risk, to tailor their initial management. Ideally, risk-adjusted treatment should implement: (1) early discharge and continuation of anticoagulation treatment at home, in the case of low-risk PE; or (2) hospital admission and clinical/haemodynamic monitoring in patients at intermediate risk, as these patients may necessitate rescue reperfusion treatment in the early period.

The principles of risk stratification of acute PE have been described, ${ }^{1}$ and anticoagulant as well as reperfusion treatment modalities have made considerable progress in the past decade. ${ }^{13}$ The challenge is now, however, to integrate all the innovative elements into a holistic treatment concept, to provide the basis for personalized, risk-adjusted care for patients with acute PE. The aim of the integrated academic clinical trial programme of the Center for Thrombosis and Hemostasis (CTH) at the University of Mainz is to develop and prospectively validate, in multinational studies, strategies for reperfusion and anticoagulant treatment of acute PE across the entire spectrum of early risk as well as clinical pathways for post-PE patient care and follow-up. This article gives an overview of the most important recently completed and on-going studies focusing on these objectives.

\section{Reperfusion Therapy of Acute PE: Beyond Cardiogenic Shock}

Recently Completed CTH Studies, Which Have Helped to Shape the Current State of the Art

The recommendations listed in the current ESC guidelines regarding the use of reperfusion therapy in normotensive patients with acute PE are largely based on the results of the international Pulmonary Embolism Thrombolysis (PEITHO) trial. ${ }^{1,14}$ PEITHO aimed to investigate the efficacy and safety of a single-bolus systemic administration of tenecteplase, in addition to standard anticoagulation therapy with heparin, in normotensive patients with intermediate-risk acute PE. Intermediate risk was defined by RV dysfunction as assessed by echocardiography or CTPA, and a positive test for cardiac troponin T or I. ${ }^{14}$ The results of PEITHO showed that, although associated with improved efficacy, systemic thrombolysis does not result in net clinical benefit if used as first-line 
treatment in patients with acute intermediate-risk PE, due to a high rate of major bleeding. ${ }^{14}$ While supporting the current recommendation that routine full-dose intravenous thrombolysis should not be prescribed to intermediate-risk patients, the results of PEITHO also highlight that safer forms of reperfusion treatment have the potential to improve the outcome of at least some of these patients at significant risk of early complications. ${ }^{11}$

Interventional reperfusion techniques, such as catheterdirected low-dose local thrombolysis (CDT), might represent a valid alternative to surgical embolectomy for selected patients with high-risk acute PE and an unacceptably high risk of major bleeding complications. Beyond this relatively narrow indication, reduced-dose systemic thrombolysis ${ }^{15,16}$ and pharmacomechanical catheter-directed reperfusion techniques ${ }^{17,18}$ are emerging as a broader alternative to standard-dose systemic lysis. In fact, in view of their presumed simplicity and safety, these modalities have also been proposed for normotensive patients with acute PE. However, the evidence to support their use in this latter setting is only based on data from cohort studies and registries, and on a small randomized trial with surrogate outcomes. ${ }^{1,17-20}$ An assessment of their efficacy and safety based on adequately sized prospective controlled trials with clinical outcomes is urgently needed. ${ }^{19}$ In particular, it needs to be confirmed that CDT, which is administered over a longer period of up to 15 to 24 hours, is indeed characterized by a low intrinsic risk in terms of major bleeding. ${ }^{21,22}$ The results of a recent pooled analysis of prospective and retrospective studies estimated a pooled rate of approximately 2 to $3 \%$ in patients undergoing CDT. ${ }^{23}$ Preliminary data on low-dose systemic thrombolysis also suggest a good safety profile, but remain to be confirmed by larger controlled trials. ${ }^{15}$

\section{Outlook and Implications for Future CTH Academic Trials on Reperfusion Treatment}

The first goal that must be achieved for the investigation of novel reperfusion therapies in clinical practice is the identification of intermediate-risk patients at risk of 'imminent' haemodynamic decompensation, given that systemic thrombolysis will remain the mainstay of treatment for patients presenting with overt haemodynamic instability. ${ }^{1,19}$ The PEITHO trial, which was designed before the criteria of PE severity were standardized in international guidelines, demanded no clinical criteria of 'severe' PE and it is therefore likely that this was one of the reasons explaining the low absolute rate of the combined primary outcome, particularly early mortality. ${ }^{14}$ Clinical baseline criteria indicating a high early decompensation risk on anticoagulant treatment alone have now been proposed on the basis of post hoc analyses of the PEITHO population. ${ }^{24}$ These criteria can be applied in future academic trials to 'enrich' the target intermediate-risk population with patients more urgently in need of pharmaceutical or pharmacomechanical reperfusion. Moreover, the impact of reperfusion strategies on long-term outcomes should also be prospectively investigated in future trials. A recent analysis of a subpopulation of PEITHO, followed for almost 3 years, suggested that thrombolysis may not influence the risk of late death or long-term complications such as chronic thromboembolic pulmonary hypertension (CTEPH) ${ }^{14,25}$ Future multinational studies, which are currently being designed at the $\mathrm{CTH}$ in collaboration with its international academic partners, will address this issue by including longer follow-up periods and by pre-specifying the assessment of clinical, functional and haemodynamic parameters best reflecting the patients' well-being over the long term.

\section{Focus on Cost-Effective Management of Low-Risk Pulmonary Embolism}

Anticoagulation represents the mainstay of therapy for acute $\mathrm{PE}$ and the prevention of its chronic complications. Anticoagulant therapy consists of an initial phase (5-10 days) of treatment with heparin or oral anticoagulation, an intermediate phase of treatment of about 3 months and an extended longterm phase for those in whom the risk of recurrence is expected to outweigh the risk of anticoagulant-related bleeding. ${ }^{9}$

Studies on early discharge and home treatment of PE conducted thus far $^{3-6}$ adopted standard anticoagulation regimens of initial subcutaneous heparin administration followed by a vitamin $\mathrm{K}$ antagonist. Only two of these trials had an inhospital comparator arm. ${ }^{3,6}$ Taken together, the results suggest that home treatment is not inferior to in-patient treatment with regard to early clinical outcomes. Despite this encouraging evidence, however, the vast majority of patients with acute PE are still treated in-hospital at the global level. ${ }^{26}$

The results of the trials investigating non-vitamin $\mathrm{K}$ antagonist oral anticoagulants (NOACs) indicate that these drugs have a non-inferior efficacy profile and an improved safety profile compared with vitamin $\mathrm{K}$ antagonists. This is true for all patients with VTE, including symptomatic acute PE. ${ }^{27}$ Moreover, single oral drug regimens for PE may minimize the patients' perceived burden of anticoagulation, and possibly the costs related to hospitalization and bleeding events. ${ }^{28}$ An optimization of PE management must therefore include the identification of low-risk patients who can be safely discharged early after diagnosis and continue with contemporary ambulatory (NOAC) treatment.

\section{Rationale and Design of the Home Treatment of Pulmonary Embolism (HoT-PE) Management Trial}

The main requirements for the identification of potential candidates for early discharge include the clinical severity of $\mathrm{PE}$, the presence and burden of co-morbidities, and the feasibility of home treatment based on the patient's family and social environment. Patients at low risk can be identified on the basis of clinical risk assessment models, notably the Pulmonary Embolism Severity Index (PESI), its simplified version (sPESI) or the Hestia decision rule. The Hestia criteria were used in three studies (607 patients), whereas the PESI formed the basis for selection in two studies (242 patients) and the SPESI in one small study (31 patients). ${ }^{29}$ Overall, both the Hestia rule and the (s)PESI clinical parameters appear capable of reliably identifying patients who are at low PErelated and overall risk. Consequently, either of them may be used for clinical triage according to local experience and preference. On the other hand, neither the PESI nor the Hestia rule provide direct information on the status of the 
$\mathrm{RV}$, a key determinant of early prognosis in acute PE. Therefore, an additional selection criterion, namely the absence of $\mathrm{RV}$ dysfunction and of free-floating thrombi in the heart on echocardiography (or CTPA), addresses the concerns generated after the premature termination of a prior randomized trial based exclusively on clinical assessment. ${ }^{6}$ In fact, accumulating data suggest that the presence of $\mathrm{RV}$ dysfunction on imaging, in patients classified as being at low risk of complications based on a clinical score (e.g., PESI) alone, may be associated with an adverse outcome $\mathrm{e}^{30,31}$; this may also be the case for a positive troponin result. ${ }^{32}$

The Home Treatment of Pulmonary Embolism (HoT-PE) study is a prospective, international, multicentre, phase IV, investigator-initiated and academically sponsored trial, aiming to determine whether early discharge and out-of-hospital treatment of low-risk acute PE patients with the oral factor Xa inhibitor rivaroxaban is feasible, effective and safe. ${ }^{33}$ In light of the already available data derived from the large phase III randomized trials and since early discharge is already being practised (therefore not requiring an 'in-hospital' control arm), the HoT-PE study was designed as a single-arm management trial ( - Fig. 1). Consecutive patients with a confirmed diagnosis of acute PE are included, if they have (1) no evidence of RV enlargement or dysfunction, and (2) no free-floating thrombi in the right heart chambers, as determined by echocardiography or CTPA $^{11}$ (-Table 1 ).

Patients enrolled in the study receive the first dose of rivaroxaban less than 2 hours before the time that the next subcutaneous injection of heparin would be due. Rivaroxaban is prescribed at the approved dose, namely $15 \mathrm{mg}$ twice daily over the first 3 weeks followed by $20 \mathrm{mg}$ once daily for a total of at least 3 months. Patients are discharged from the hospital within 48 hours of presentation. The primary efficacy outcome is symptomatic recurrent VTE or PE-related death within 3 months of enrolment. The secondary efficacy outcomes include all-cause mortality, overall duration of hospital stay, the number of re-hospitalizations due to PE or to a bleeding event, generic and disease-specific quality of life, treatment satisfaction and the utilization of health care resources at 3 weeks and 3 months. All outcomes are adjudicated by an independent committee.

HoT-PE is registered under the identifier of EudraCT number 2013-001657-28. The enrolment of the last patient is expected by November 2018, depending on the results of the pre-specified interim analysis after the inclusion of 525 patients in July 2018.

\section{Adjusted Initial Anticoagulation Concept for Intermediate-Risk Pulmonary Embolism}

Normotensive patients at intermediate risk, i.e. with at least one indicator of elevated PE-related risk, or with aggravating conditions or comorbidity, should be hospitalized. Within this group, patients with signs of RV dysfunction on echocardiography or CTPA accompanied by a positive troponin test should be monitored over the first hours or days due to the risk of early haemodynamic decompensation and circulatory collapse. ${ }^{14}$ Primary reperfusion treatment, notably full-dose systemic thrombolysis, is not routinely recommended in these patients, since the risk of potentially life-threatening bleeding complications appears too high. ${ }^{14}$ However, rescue thrombolytic therapy or, alternatively, surgical embolectomy or percutaneous catheter-directed treatment may become necessary for patients who develop signs of haemodynamic instability. ${ }^{1}$

\section{Rationale and Design of the Pulmonary Embolism International Trial (PEITHO)-2}

Patients diagnosed with intermediate-risk PE represent as many as $50 \%$ of all patients with acute PE and are characterized by a substantial risk of developing early adverse outcomes ( $\sim 8 \%$ overall). All NOACs approved for the treatment of acute VTE have been tested in large phase III trials including a

\section{STUDY PERIOD}

follow-up visits at 8 days, 3 weeks and 3 months (additional check of vital status at 12 months)

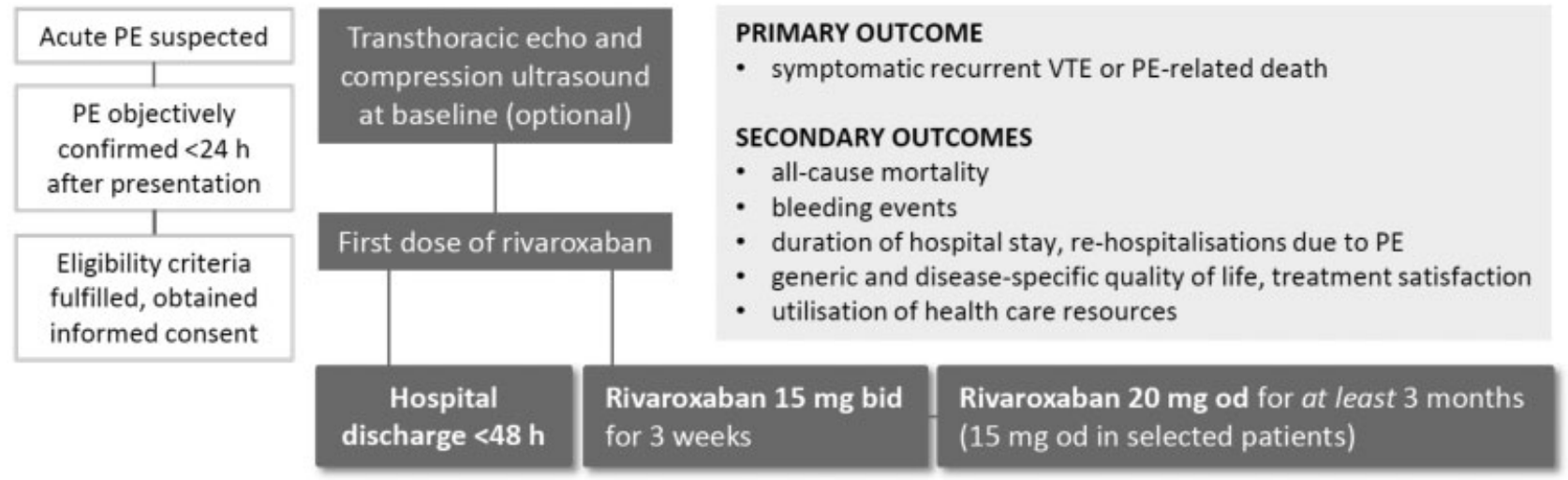

Fig. 1 Overview of the Home Treatment of Pulmonary Embolism (HoT-PE) management study. bid, twice daily; od, once daily; PE, pulmonary embolism; VTE, venous thromboembolism. (Reproduced with permission from Barco et al. ${ }^{33}$ ) 
Table 1 Inclusion and exclusion criteria of the HoT-PE (Home Treatment of Pulmonary Embolism) study

\begin{tabular}{|c|c|}
\hline Inclusion criteria & Exclusion criteria \\
\hline $\begin{array}{l}\text { 1. Age } \geq 18 \text { y } \\
\text { 2. Objectively confirmed diagnosis of acute PE by multide- } \\
\text { tector CT, V/Q lung scan or selective pulmonary angio- } \\
\text { graphy, according to established diagnostic criteria, with or } \\
\text { without symptomatic DVT } \\
\text { 3. Absence of RV enlargement or dysfunction, and of free- } \\
\text { floating thrombi in the right atrium or right ventricle on } \\
\text { echocardiography or CT. On echocardiography, RV dys- } \\
\text { function is absent when both of the following criteria listed } \\
\text { below are met: } \\
\text { i. Right/left ventricular end-diastolic diameter ratio } \leq 0.9 \\
\text { (apical or subcostal } 4 \text {-chamber view) } \\
\text { ii. No paradoxical motion of the interventricular septum } \\
\text { On CT, RV enlargement is absent when the following } \\
\text { criterion is met: right/left short-axis diameter ratio } \\
\text { 4. Ability of patient to understand the character and con- } \\
\text { sequences of a clinical trial } \\
\text { 5. For women of childbearing potential, negative pregnancy } \\
\text { test before enrolment and medically accepted contracep- } \\
\text { tion throughout the trial } \\
\text { 6. Signed and dated informed consent of the patient available } \\
\text { before the start of any trial procedures }\end{array}$ & $\begin{array}{l}\text { 1. Haemodynamic instability at presentation } \\
\text { 2. Use of a fibrinolytic agent, surgical thrombectomy, inter- } \\
\text { ventional (transcatheter) thrombus aspiration or lysis, or } \\
\text { use of a cava filter to treat the index episode of PE } \\
\text { 3. Active bleeding or known significant bleeding risk } \\
\text { 4. Need for supplemental oxygen administration to maintain } \\
\text { oxygen saturation }>90 \% \\
\text { 5. Chronic treatment with a vitamin K antagonist, rivaroxaban } \\
\text { or any other oral or parenteral anticoagulant drug } \\
\text { 6. Pain requiring parenteral administration of analgesic } \\
\text { agents } \\
\text { 7. Other medical conditions/comorbidities requiring hospi- } \\
\text { talization } \\
\text { 8. Acute PE diagnosed in a patient already hospitalized for } \\
\text { another condition } \\
\text { 9. Non-compliance or inability to adhere to treatment or to } \\
\text { the follow-up visits; or lack of a family environment or } \\
\text { support system for home treatment } \\
\text { 10. Severe renal insufficiency (eGFR }<15 \text { mL/min/1.73 m }{ }^{2} \text { by } \\
\text { the MDRD formula), or end-stage renal disease } \\
\text { 11. Severe hepatic failure } \\
\text { 12. Pregnancy or lactation } \\
\text { 13. History of hypersensitivity to the study drug } \\
\text { 14. Treatment of the acute (index) episode with unfractio- } \\
\text { nated heparin, low-molecular-weight heparin, fondapar- } \\
\text { inux or a new oral anticoagulant for more than } 48 \text { hours, } \\
\text { or with more than a single dose of a vitamin } \mathrm{K} \text { antagonist } \\
\text { prior to inclusion in the study } \\
\text { 15. Concomitant administration of strong inhibitors of P-gP } \\
\text { and CYP3A4 such as azole antimycotic agents or HIV } \\
\text { protease inhibitors } \\
\text { 16. Need for long-term treatment vitamin } \mathrm{K} \text { antagonists, or } \\
\text { for antiplatelet agents except acetylsalicylic acid at a } \\
\text { dosage } \leq 100 \text { mg/d } \\
\text { 17. Participation in other clinical trials within the last } 6 \\
\text { months } \\
\text { 18. Medical or psychological condition that would not permit } \\
\text { completion of the trial or signing of informed consent } \\
\text { 19. Life expectancy less than } 3 \text { months }\end{array}$ \\
\hline
\end{tabular}

Abbreviations: CT, computed tomography; DVT, deep vein thrombosis; eGFR, estimated glomerular filtration rate; HIV, human immunodeficiency virus; MDRD, Modified Diet in Renal Disease formula for calculation of the glomerular filtration rate; PE, pulmonary embolism; RV, right ventricular; $\mathrm{V} / \mathrm{Q}$, ventilation-perfusion (lung scan).

andicated by at least one of the following criteria: (1) systemic blood pressure less than $100 \mathrm{~mm} \mathrm{Hg}$, or heart rate above 100 bpm, or a drop in systemic blood pressure by more than $40 \mathrm{~mm} \mathrm{Hg}$ for at least 15 minutes; (2) need for catecholamines to maintain organ perfusion and systolic blood pressure above $100 \mathrm{~mm} \mathrm{Hg}$; (3) need for cardiopulmonary resuscitation.

significant proportion of patients with acute PE. However, their safety and efficacy have not been systematically investigated in patients enrolled based on their risk class. A post-hoc analysis of the Hokusai-VTE study, which compared edoxaban versus standard of care (warfarin), focused on patients with intermediate-risk PE, as defined by positive N-terminal probrain natriuretic peptide (NT-proBNP) and right to left ventricular diameter ratio on CTPA as indicators of RV dysfunction. The results suggested that recurrent VTE rates were lower with edoxaban than warfarin. ${ }^{34}$

The ongoing PEITHO-2 (Pulmonary Embolism International Trial-2) study is a prospective, multicentre, multinational, single-arm trial aiming to investigate whether acute intermediate-risk PE patients can be safely managed with a short-term course of parenteral heparin anticoagulation over the first 72 hours, followed by the direct oral thrombin inhibitor dabigatran at the dosage of $150 \mathrm{mg}$ twice daily over 6 months (-Fig. 2). A reduced dose of $110 \mathrm{mg}$ twice daily is recommended for patients aged 80 years or older and for those receiving verapamil, according to the European Summary of Product Characteristics. Patients with objectively confirmed diagnosis of symptomatic acute intermediaterisk PE, with or without symptomatic deep vein thrombosis, who are haemodynamically stable at presentation, are eligible for enrolment in the study (-Table 2). The key inclusion criteria include the absence of haemodynamic decompensation or collapse at presentation, and the presence of intermediate-risk PE, as defined by elevated troponin levels or NT-proBNP, or by RV pressure dysfunction/enlargement on echocardiography or CTPA. 


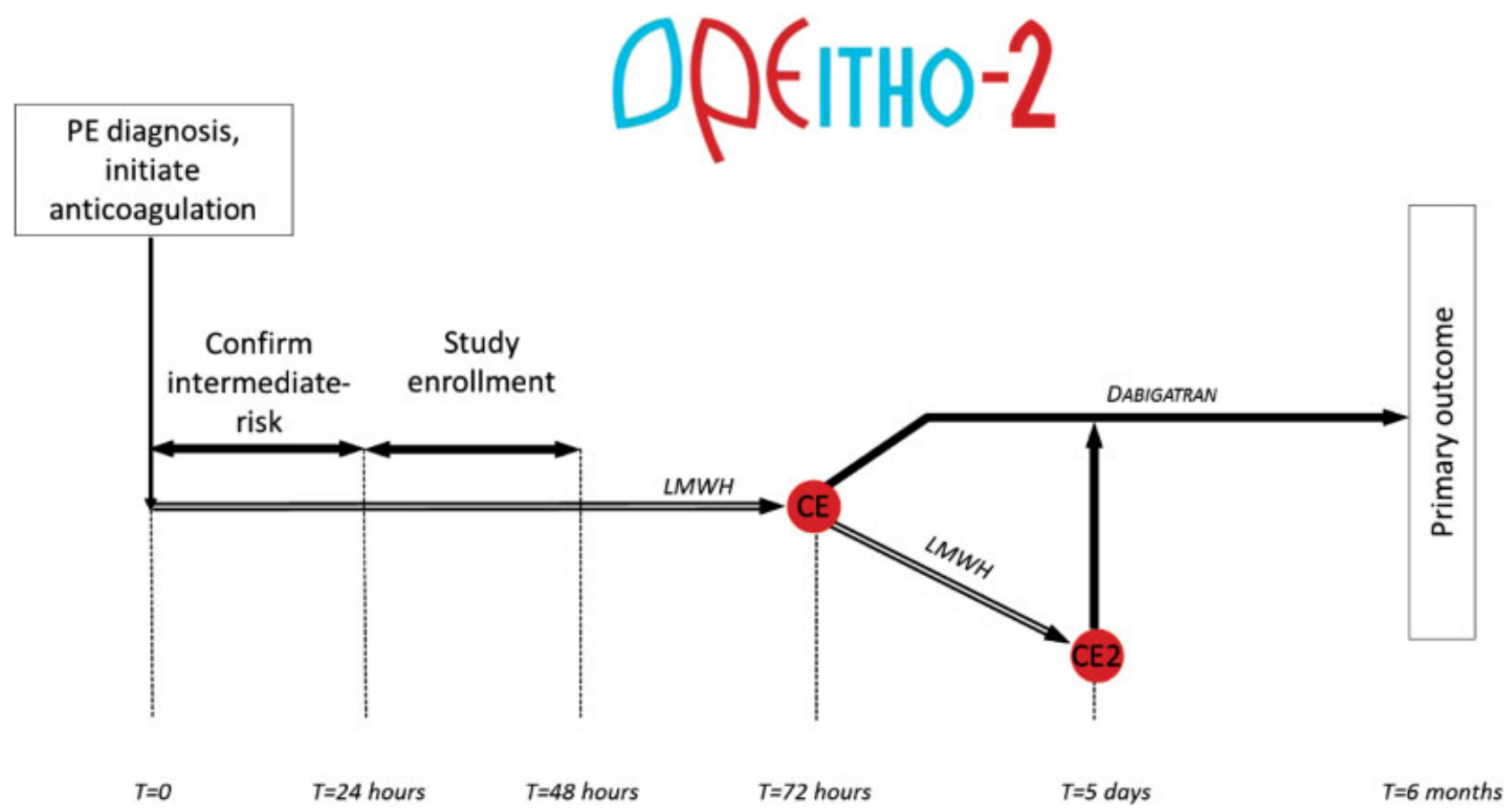

Fig. 2 Overview of design of the PEITHO-2 (Pulmonary Embolism International Trial-2) study. CE, clinical evaluation; I, inclusion; LMWH, lowmolecular-weight heparin; PE, pulmonary embolism; T, time. (Reproduced with permission from Klok et al. ${ }^{50}$ )

Table 2 Inclusion and exclusion criteria of PEITHO-2 (Pulmonary Embolism International Trial-2)

\begin{tabular}{|c|c|}
\hline Inclusion criteria & Exclusion criteria \\
\hline $\begin{array}{l}\text { 1. Age } \geq 18 \text { y } \\
\text { 2. Objectively confirmed diagnosis of acute PE, with or with- } \\
\text { out DVT } 1 \\
\text { 3. No haemodynamic decompensation or collapse at pre- } \\
\text { sentation (none of the following): } \\
\text { i. Need for cardiopulmonary resuscitation; } \\
\text { ii. Systolic BP }<90 \mathrm{~mm} \mathrm{Hg} \text {, or drop by } \geq 40 \mathrm{~mm} \mathrm{Hg} \text {, for } \\
\text { at least } 15 \text { minutes, with clinical signs of end-organ } \\
\text { hypoperfusion (cold extremities, urinary output }<30 \\
\text { mL/h, mental confusion) } \\
\text { iii. Need for catecholamines to maintain adequate organ } \\
\text { perfusion and a systolic BP of }>90 \mathrm{~mm} \text { Hg } \\
\text { 4. Intermediate-risk PE ( } \geq 1 \text { of the a, b or c criteria): } \\
\text { a. Elevated troponin levels } \\
\text { b. NT-proBNP levels }>600 \text { pg/mL } \\
\text { c. RV pressure overload/dysfunction on CT angiography or } \\
\text { echocardiography: } \\
\text { i. CTPA: RV/LV end-diastolic diameter ratio }>1.0 \\
\text { ii. echocardiography (any of the following): } \\
\text { - RV/LV end-diastolic diameter ratio }>1.0 \text { (apical or } \\
\text { subcostal } 4 \text {-chamber view) } \\
\text { - RV end-diastolic diameter }>30 \mathrm{~mm} \text { (parasternal } \\
\text { long-axis or short-axis view) } \\
\text { - RV free wall hypokinesis (any view) } \\
\text { - Tricuspid regurgitant jet velocity }>2.6 \mathrm{~m} / \mathrm{s} \\
\text { - Absence of inspiratory collapse of the inferior vena } \\
\text { cava }\end{array}$ & $\begin{array}{l}\text { 1. Any medical or psychological condition that would not } \\
\text { permit signing of informed consent or completion of the } \\
\text { trial; unwillingness or inability to adhere to treatment or to } \\
\text { the follow-up visits } \\
\text { 2. Pregnancy or lactation (or women of childbearing potential } \\
\text { not practising a medically accepted contraception during } \\
\text { the trial) } \\
\text { 3. History of hypersensitivity to dabigatran } \\
\text { 4. Use of a fibrinolytic agent, surgical embolectomy, inter- } \\
\text { ventional (catheter-directed) thrombus aspiration or lysis, } \\
\text { or use of a vena cava filter } \\
\text { 5. Active bleeding or known significant bleeding risk } \\
\text { 6. Need for long-term treatment with any anticoagulant, or } \\
\text { need for antiplatelet agents except acetylsalicylic acid } \\
\leq 100 \mathrm{mg} / \mathrm{d} \\
\text { 7. Artificial heart valves requiring treatment with an antic- } \\
\text { oagulant } \\
\text { 8. Renal insufficiency with estimated creatinine clearance } \\
<30 \mathrm{~mL} / \mathrm{min} / 1.73 \mathrm{~m}^{2} \\
\text { 9. Chronic liver disease with aminotransferase levels two } \\
\text { times or more above the local upper limit of normal range } \\
\text { 10. Concomitant administration of strong inhibitors of P- } \\
\text { glycoprotein like ketoconazole, cyclosporin, itraconazole } \\
\text { or dronedarone } \\
\text { 11. Life expectancy less than } 6 \text { months }\end{array}$ \\
\hline
\end{tabular}

Abbreviations: BP, blood pressure; CTPA, computed tomography pulmonary angiography; DVT, deep vein thrombosis; LV, left ventricular; NT-proBNP, N-terminal pro brain natriuretic peptide; PE, pulmonary embolism; RV, right ventricular; VTE, venous thromboembolism.

a Troponin elevation is defined as an abnormal result of any validated troponin test based on the reference values determined by the local Department of Clinical Chemistry at each participating site. 
The primary efficacy outcome is recurrent symptomatic VTE or death related to PE within the first 6 months. The primary safety outcome is major bleeding as defined by the International Society on Thrombosis and Haemostasis (ISTH). Secondary outcomes include all-cause mortality, the overall duration of hospital stay (index event and repeated hospitalizations) and the temporal pattern of recovery of right ventricular function over the 6-month follow-up period. All outcomes are adjudicated by an independent committee.

The PEITHO-2 study (EudraCT No.: 2015-001830-12) will determine which patients within the large group and broad spectrum of intermediate-risk PE may need initial heparin treatment and monitoring, and how long this initial parenteral phase should last. Finally, the PEITHO-2 study will contribute to determine the extent and speed of cardiac recovery after acute PE, and its prognostic role over the long term.

\section{Long-Term Follow-up and Late Outcome after Acute PE}

The risk to die or develop persistent serious disability after acute PE declines over time but remains elevated for months or years, reflecting in part the severity of the initial event and the burden of the individual's comorbidity. ${ }^{9}$ More specifically, recurrent VTE occurs in approximately $22 \%$ of patients after 5 years, ${ }^{35}$ whereas a small but non-negligible proportion ( $3 \%$ ) of PE survivors are expected to develop CTEPH during the first 2 years of follow-up. ${ }^{36}$

CTEPH is thought to result from incomplete resolution of pulmonary emboli ${ }^{1,37}$; therefore, appropriate management of (and after) acute PE may help limit its occurrence. Although the diagnosis and management of CTEPH have made considerable progress in recent years, ${ }^{38,39}$ its clinical and haemodynamic predictors and/or prodromes, starting at diagnosis of acute PE, have not been prospectively investigated and determined. Since CTEPH is a potentially devastating, but also surgically 'curable', obstructive disease of the pulmonary vessels with thrombofibrotic material, its prediction and early identification may significantly improve the outcome of these patients. ${ }^{40}$

Beyond the objective not to miss clinically manifest CTEPH, the clinical follow-up of PE patients after the (presumed) index PE event as well as the elaboration of a cost effective 'post-PE' management algorithm represents a complex, unaccomplished task. It is established, as reviewed in Klok and Barco, ${ }^{41}$ that

Table 3 Design and data collection schedule of the follow-up after acute pulmonary embolism (FOCUS) study

\begin{tabular}{|c|c|c|c|c|c|}
\hline \multirow[t]{2}{*}{ Variable } & \multicolumn{2}{|l|}{ In-hospital } & \multicolumn{3}{|c|}{ Follow-up } \\
\hline & Enrolment & Discharge & $3 \mathrm{mo}$ & $12 \mathrm{mo}$ & $24 \mathrm{mo}$ \\
\hline Medical history & $\mathrm{x}$ & & & & \\
\hline Demographic data $^{\mathrm{a}}$ & $x$ & & & & \\
\hline Clinical examination $^{\mathrm{b}}$ & $\mathrm{x}$ & & $\mathrm{x}$ & $x$ & $x$ \\
\hline Imaging (PE diagnosis) & $\mathrm{x}$ & & & & \\
\hline Echocardiography & $x$ & $x$ & $x$ & $x$ & $x$ \\
\hline Cardiopulmonary exercise testing & & & $\mathrm{x}$ & $\mathrm{x}$ & $\mathrm{x}$ \\
\hline Laboratory diagnostic and safety tests ${ }^{c}$ & $\mathrm{x}$ & $\mathrm{x}$ & $\mathrm{x}$ & $\mathrm{x}$ & $\bar{x}$ \\
\hline Pharmacological treatment & $x$ & $x$ & $x$ & $x$ & $x$ \\
\hline Haemodynamic collapse & $x$ & $\mathrm{x}$ & $\mathrm{x}$ & $x$ & $x$ \\
\hline Survival status & & $\mathrm{x}$ & $\mathrm{x}$ & $\mathrm{x}$ & $\mathrm{x}$ \\
\hline Re-hospitalization & & & $\mathrm{x}$ & $x$ & $x$ \\
\hline Stroke & & $x$ & $x$ & $x$ & $x$ \\
\hline Symptomatic recurrent DVT/PE & & $\mathrm{x}$ & $\mathrm{x}$ & $\mathrm{x}$ & $\mathrm{x}$ \\
\hline Bleeding events & & $x$ & $x$ & $x$ & $x$ \\
\hline Functional status $^{\mathrm{d}}$ & & & $x$ & $x$ & $x$ \\
\hline Diagnostic work-up for CTEPH & & & $x$ & $x$ & $x$ \\
\hline Generic quality of life $\mathrm{f}^{\mathrm{f}}$ & & & $\mathrm{x}$ & $x$ & $x$ \\
\hline Disease-specific quality of life ${ }^{g}$ & & & $\mathrm{x}$ & $\mathrm{x}$ & $\bar{x}$ \\
\hline
\end{tabular}

Abbreviations; CTEPH, chronic thromboembolic pulmonary hypertension; DVT, deep vein thrombosis; PE, pulmonary embolism.

Source: Adapted from Konstantinides et al. ${ }^{45}$

aDate of birth, gender, height, weight.

bPresentation and symptomatology, vital signs; 12-lead ECG.

'Serum creatinine, creatinine clearance (MDRD-estimate), TSH, $\mathrm{O}_{2}$-saturation (pulse oximetry), haematocrit, thrombocytes, leucocytes, aPTT, PT, INR, troponin T or I, NT-pro-BNP, BNP, CRP, D-dimer.

${ }^{\mathrm{d}} \mathrm{WHO}$ functional class, Borg dyspnoea index.

${ }^{e} \mathrm{CT}$ pulmonary angiography, V/Q scan; selective pulmonary angiography, right heart catheterization.

${ }^{f} \mathrm{EQ}-5 \mathrm{D}$ questionnaire. ${ }^{46}$

${ }^{9}$ PEmb-QoL questionnaire. ${ }^{47}$ 
dyspnoea and/or poor physical performance may persist in up to $50 \%$ of patients 6 months to 3 years after the index PE, and up to $75 \%$ may perceive their own health status as being 'worse' than before the acute PE episode. The concept of post-PE impairment (PPEI), or the 'post-PE syndrome', has been proposed to provide an umbrella for a rather heterogeneous group of patients presenting with complaints and/or abnormal clinical findings, along with imaging, functional or haemodynamic abnormalities, several months or years acute PE. In the minority of cases, these findings will be followed by the development of CTEPH. ${ }^{42-45}$ The definition of PPEI is still evolving, and its characteristics and the potential predictors of further functional worsening remain to be identified.

\section{Rationale and Design of the Follow-up after Acute Pulmonary Embolism (FOCUS) Cohort Study}

The prospective FOCUS cohort study aims to answer clinically relevant questions regarding the predictors and prognostic factors of the transition from acute PE to PPEI and (possibly) CTEPH. In this multicentre patient cohort, the participating sites are large-volume expert centres, which have standardized and harmonized their existing follow-up programmes after acute PE; they prospectively enrol consecutive, unselected symptomatic PE patients and collect data during follow-up visits at predefined intervals ( - Table 3 ). A predefined sample size of more than 1,000 patients will allow adequate estimation of PPEI or CTEPH rates as well as a prospective assessment of the changes leading to PPEI, which has been prospectively defined in this study by a combination of clinical, functional, haemodynamic and imaging abnormalities ( - Table 4). The approach of viewing CTEPH as part of a continuum of late PE sequelae has its rationale in the assumption that persisting or progressive functional and/or haemodynamic impairment after acute PE is an early indicator of the development of CTEPH.

FOCUS enrols all-comers, i.e., unselected patients with acute $\mathrm{PE}$, irrespectively of the clinical severity, evidence

Table 4 Primary, secondary and safety outcomes of FOCUS

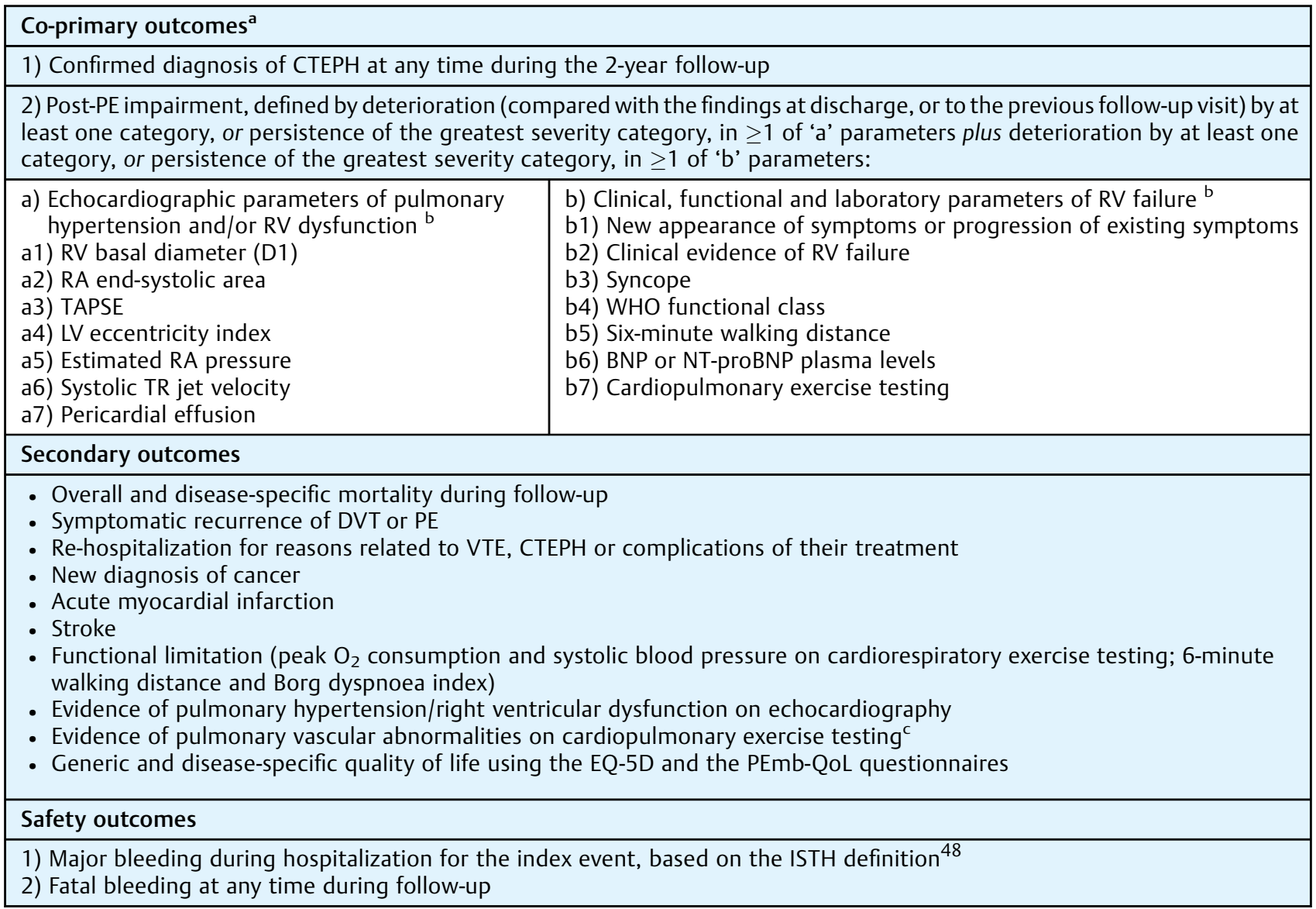

Abbreviations: BNP, brain natriuretic peptide; CTEPH, chronic thromboembolic pulmonary hypertension; EQ-5D, Euro Quality of life five dimensions (questionnaire); ISTH, International Society on Thrombosis and Haemostasis; NT-proBNP, N-terminal pro-brain natriuretic peptide; PE, pulmonary embolism; PEmb-QoL, Pulmonary Embolism Quality of Life (questionnaire); RA, right atrial; RV, right ventricular; TAPSE, tricuspid annular plane systolic excursion; TR, tricuspid regurgitation; VTE, venous thromboembolism; WHO, World Health Organization.

Source: Adapted from Konstantinides et al. ${ }^{45}$

${ }^{a}$ See statistical analysis for details.

bSee - Table 3 for severity classification of individual findings and parameters.

Indicated by at least one of the following: $\mathrm{PETCO}_{2}$ at AT (end-tidal partial carbon dioxide pressure at anaerobic threshold) $<31.33 \mathrm{~mm} \mathrm{Hg} ; \mathrm{P}(\mathrm{a}-\mathrm{ET}$ ) $\mathrm{CO}_{2}>5.18 \mathrm{~mm} \mathrm{Hg}$; EQ O $\mathrm{O}_{2}$ (oxygen ventilatory equivalent) $>30.5 ; \mathrm{EQ} \mathrm{CO}_{2}$ (carbon dioxide ventilatory equivalent) $>35.5 ; \mathrm{VE} / \mathrm{VCO} 2$ slope (ventilator efficiency for carbon dioxide) $>37.5 ; \mathrm{P}(\mathrm{A}-\mathrm{a}) \mathrm{O}_{2}$ (alveolar-arterial oxygen gradient) $>36.97 \mathrm{~mm} .{ }^{49}$ 
and degree of RV dysfunction, or characteristics of PE. The primary objective of the study is to determine the cumulative (2-year) incidence of: (1) CTEPH and (2) persisting or progressive functional and/or haemodynamic PPEI ( - Table 4$)$. Secondary objectives are to determine overall and disease-specific long-term mortality, the incidence of major adverse cardiovascular events, predictors as well as indicators of functional/ haemodynamic impairment, fatal bleeding complications associated with long-term anticoagulant treatment for VTE and the patients' generic and disease-specific quality of life. All outcomes are adjudicated by an independent clinical events committee. A multicentre biobanking substudy 'Biochemical and Genetic Biomarkers in Sequelae of Acute Pulmonary Embolism Study (FOCUS BioSeq)' is being conducted within the FOCUS cohort. The study has been registered in the German Clinical Trials registry (www.germanctr.de; identifier: DRKS00005939). Enrolment of the last patient was in October 2018; the 2-year follow-up will be completed 2 years later.

\section{Conclusion}

The concept of risk-adapted management of acute PE is relatively novel and is leading to considerable improvement in clinical care. Present and future challenge is represented by further implementation and systematic introduction into clinical practice of personalized, riskadjusted management strategies. The aim of the integrated academic clinical trial programme of the CTH at the University of Mainz is to develop and prospectively validate, in multinational studies, such strategies for the acute management, as well as long-term patient care and followup, of acute PE.

\section{Financial Support and Sponsorship}

The work of Stefano Barco and Stavros V. Konstantinides is supported by the German Federal Ministry of Education and Research (BMBF $01 \mathrm{EO} 003$ and 01EO1503).

\section{Conflicts of Interest}

Stefano Barco has received an educational travel grant from Daiichi Sankyo and Bayer HealthCare.

Stavros V. Konstantinides has received consultancy and lecture honoraria from the Wyss Institute and Boehringer Ingelheim, and institutional grants from Boehringer Ingelheim.

\section{References}

1 Konstantinides SV, Torbicki A, Agnelli G, et al; Task Force for the Diagnosis and Management of Acute Pulmonary Embolism of the European Society of Cardiology (ESC). 2014 ESC guidelines on the diagnosis and management of acute pulmonary embolism. Eur Heart J 2014;35(43):3033-3069, 3069a-3069k

2 Cohen AT, Agnelli G, Anderson FA, et al; VTE Impact Assessment Group in Europe (VITAE). Venous thromboembolism (VTE) in Europe. The number of VTE events and associated morbidity and mortality. Thromb Haemost 2007;98(04):756-764

3 Naess IA, Christiansen SC, Romundstad P, Cannegieter SC, Rosendaal FR, Hammerstrøm J. Incidence and mortality of venous thrombosis: a population-based study. J Thromb Haemost 2007;5(04):692-699
4 Alotaibi GS, Wu C, Senthilselvan A, McMurtry MS. Secular trends in incidence and mortality of acute venous thromboembolism: the AB-VTE population-based study. Am J Med 2016;129(08):879. e19-879.e25

5 Barco S, Woersching AL, Spyropoulos AC, Piovella F, Mahan CE. European Union-28: an annualised cost-of-illness model for venous thromboembolism. Thromb Haemost 2016;115(04):800-808

6 Mahan CE, Borrego ME, Woersching AL, et al. Venous thromboembolism: annualised United States models for total, hospitalacquired and preventable costs utilising long-term attack rates. Thromb Haemost 2012;108(02):291-302

7 Mahan CE, Barco S, Spyropoulos AC. Cost-of-illness model for venous thromboembolism. Thromb Res 2016;145:130-132

8 Hobohm L, Hellenkamp K, Hasenfuß G, Münzel T, Konstantinides S, Lankeit M. Comparison of risk assessment strategies for not-highrisk pulmonary embolism. Eur Respir J 2016;47(04):1170-1178

9 Konstantinides SV, Barco S, Lankeit M, Meyer G. Management of pulmonary embolism: an update. J Am Coll Cardiol 2016;67(08): 976-990

10 Kasper W, Konstantinides S, Geibel A, et al. Management strategies and determinants of outcome in acute major pulmonary embolism: results of a multicenter registry. J Am Coll Cardiol 1997;30(05):1165-1171

11 Becattini C, Agnelli G, Lankeit M, et al. Acute pulmonary embolism: mortality prediction by the 2014 European Society of Cardiology risk stratification model. Eur Respir J 2016;48(03): 780-786

12 Kearon C, Akl EA, Ornelas J, et al. Antithrombotic therapy for VTE disease: CHEST guideline and expert panel report. Chest 2016; 149(02):315-352

13 Huisman MV, Barco S, Cannegieter SC, et al. Pulmonary embolism. Nat Rev Dis Primers 2018;4:18028

14 Meyer G, Vicaut E, Danays T, et al; PEITHO Investigators. Fibrinolysis for patients with intermediate-risk pulmonary embolism. $\mathrm{N}$ Engl J Med 2014;370(15):1402-1411

15 Sharifi M, Bay C, Skrocki L, Rahimi F, Mehdipour M. "MOPETT" Investigators. Moderate pulmonary embolism treated with thrombolysis (from the "MOPETT" Trial). Am J Cardiol 2013;111 (02):273-277

16 Wang C, Zhai Z, Yang Y, et al; China Venous Thromboembolism (VTE) Study Group. Efficacy and safety of low dose recombinant tissue-type plasminogen activator for the treatment of acute pulmonary thromboembolism: a randomized, multicenter, controlled trial. Chest 2010;137(02):254-262

17 Kucher N, Boekstegers P, Müller OJ, et al. Randomized, controlled trial of ultrasound-assisted catheter-directed thrombolysis for acute intermediate-risk pulmonary embolism. Circulation 2014; 129(04):479-486

18 Piazza G, Hohlfelder B, Jaff MR, et al; SEATTLE II Investigators. A prospective, single-arm, multicenter trial of ultrasound-facilitated, catheter-directed, low-dose fibrinolysis for acute massive and submassive pulmonary embolism: the SEATTLE II study. JACC Cardiovasc Interv 2015;8(10):1382-1392

19 Barco S, Konstantinides SV. Risk-adapted management of pulmonary embolism. Thromb Res 2017;151(Suppl 1):S92-S96

20 Kuo WT, Banerjee A, Kim PS, et al. Pulmonary Embolism Response to Fragmentation, Embolectomy, and Catheter Thrombolysis (PERFECT): initial results from a prospective multicenter registry. Chest 2015;148(03):667-673

21 Jaber WA, Fong PP, Weisz G, Lattouf O, Jenkins J, Rosenfield K, Rab T, Ramee S. Acute Pulmonary Embolism: With an Emphasis on an Interventional Approach. J Am Coll Cardiol. 2016; 1;67(08): 991-1002

22 Tapson VF, Sterling K, Jones N, Elder M, Tripathy U, Brower J, Maholic RL, Ross CB, Natarajan K, Fong P, Greenspon L, Tamaddon H, Piracha AR, Engelhardt T, Katopodis J, Marques V, Sharp ASP, Piazza G, Goldhaber SZ. A Randomized Trial of the Optimum Duration of Acoustic Pulse Thrombolysis Procedure in Acute 
Intermediate-Risk Pulmonary Embolism: The OPTALYSE PE Trial. JACC Cardiovasc Interv 2018;11(14):1401-1410

23 Bajaj NS, Kalra R, Arora P, et al. Catheter-directed treatment for acute pulmonary embolism: systematic review and single-arm meta-analyses. Int J Cardiol 2016;225:128-139

24 Barco S, Vicaut E, Klok FA, Lankeit M, Meyer G, Konstantinides SV; PEITHO Investigators. Improved identification of thrombolysis candidates amongst intermediate-risk pulmonary embolism patients: implications for future trials. Eur Respir J 2018;51 (01):1701775

25 Konstantinides SV, Vicaut E, Danays T, et al. Impact of thrombolytic therapy on the long-term outcome of intermediate-risk pulmonary embolism. J Am Coll Cardiol 2017;69(12):1536-1544

26 Dentali F, Di Micco G, Giorgi Pierfranceschi M, et al. Rate and duration of hospitalization for deep vein thrombosis and pulmonary embolism in real-world clinical practice. Ann Med 2015; 47(07):546-554

27 Dentali F, Di Minno MN, Gianni M, Ambrosino P, Squizzato A, Ageno W. Non-vitamin $\mathrm{K}$ oral anticoagulants in patients with pulmonary embolism: a systematic review and meta-analysis of the literature. Intern Emerg Med 2015;10(04):507-514

28 Jun M, Lix LM, Durand M, et al; Canadian Network for Observational Drug Effect Studies (CNODES) Investigators. Comparative safety of direct oral anticoagulants and warfarin in venous thromboembolism: multicentre, population based, observational study. BMJ 2017;359:j4323

29 Roy PM, Moumneh T, Penaloza A, Sanchez O. Outpatient management of pulmonary embolism. Thromb Res 2017;155:92-100

30 Côté B, Jiménez D, Planquette B, et al. Prognostic value of right ventricular dilatation in patients with low-risk pulmonary embolism. Eur Respir J 2017;50(06):1701611

31 Jimenez D, Lobo JL, Fernandez-Golfin C, et al; PROTECT investigators. Effectiveness of prognosticating pulmonary embolism using the ESC algorithm and the Bova score. Thromb Haemost 2016;115(04):827-834

32 Darwish OS, Mahayni A, Patel M, Amin A. Cardiac troponins in low-risk pulmonary embolism patients: a systematic review and meta-analysis. J Hosp Med 2018;13(10):706-712

33 Barco S, Lankeit M, Binder $\mathrm{H}$, et al. Home treatment of patients with low-risk pulmonary embolism with the oral factor Xa inhibitor rivaroxaban. Rationale and design of the HoT-PE Trial. Thromb Haemost 2016;116(01):191-197

34 Brekelmans MP, Ageno W, Beenen LF, et al. Recurrent venous thromboembolism in patients with pulmonary embolism and right ventricular dysfunction: a post-hoc analysis of the HokusaiVTE study. Lancet Haematol 2016;3(09):e437-e445

35 Baglin T, Douketis J, Tosetto A, et al. Does the clinical presentation and extent of venous thrombosis predict likelihood and type of recurrence? A patient-level meta-analysis. J Thromb Haemost 2010;8(11):2436-2442

36 Ende-Verhaar YM, Cannegieter SC, Vonk Noordegraaf A, et al. Incidence of chronic thromboembolic pulmonary hypertension after acute pulmonary embolism: a contemporary view of the published literature. Eur Respir J 2017;49(02):1601792

37 Lang IM, Pesavento R, Bonderman D, Yuan JX. Risk factors and basic mechanisms of chronic thromboembolic pulmonary hyper- tension: a current understanding. Eur Respir J 2013;41(02): 462-468

38 Galiè N, Humbert M, Vachiery JL, et al; ESC Scientific Document Group. 2015 ESC/ERS Guidelines for the diagnosis and treatment of pulmonary hypertension: The Joint Task Force for the Diagnosis and Treatment of Pulmonary Hypertension of the European Society of Cardiology (ESC) and the European Respiratory Society (ERS): Endorsed by: Association for European Paediatric and Congenital Cardiology (AEPC), International Society for Heart and Lung Transplantation (ISHLT). Eur Heart J 2016;37(01): 67-119

$39 \mathrm{Kim} \mathrm{NH}$, Delcroix M, Jenkins DP, et al. Chronic thromboembolic pulmonary hypertension. J Am Coll Cardiol 2013;62(25, Suppl): D92-D99

40 Pepke-Zaba J, Delcroix M, Lang I, et al. Chronic thromboembolic pulmonary hypertension (CTEPH): results from an international prospective registry. Circulation 2011;124(18):1973-1981

41 Klok FA, Barco S. Follow-up after acute pulmonary embolism. Hamostaseologie 2018;38(01):22-32

42 Kahn SR, Hirsch AM, Akaberi A, et al. Functional and exercise limitations after a first episode of pulmonary embolism: results of the ELOPE prospective cohort study. Chest 2017;151(05): 1058-1068

43 Sista AK, Miller LE, Kahn SR, Kline JA. Persistent right ventricular dysfunction, functional capacity limitation, exercise intolerance, and quality of life impairment following pulmonary embolism: systematic review with meta-analysis. Vasc Med 2017;22(01): 37-43

44 Klok FA, van der Hulle T, den Exter PL, Lankeit M, Huisman MV, Konstantinides S. The post-PE syndrome: a new concept for chronic complications of pulmonary embolism. Blood Rev 2014;28(06):221-226

45 Konstantinides SV, Barco S, Rosenkranz S, et al. Late outcomes after acute pulmonary embolism: rationale and design of FOCUS, a prospective observational multicenter cohort study. J Thromb Thrombolysis 2016;42(04):600-609

46 Herdman M, Gudex C, Lloyd A, et al. Development and preliminary testing of the new five-level version of EQ-5D (EQ-5D-5L). Qual Life Res 2011;20(10):1727-1736

47 Klok FA, Cohn DM, Middeldorp S, et al. Quality of life after pulmonary embolism: validation of the PEmb-QoL Questionnaire. J Thromb Haemost 2010;8(03):523-532

48 Schulman S, Kearon C; Subcommittee on Control of Anticoagulation of the Scientific and Standardization Committee of the International Society on Thrombosis and Haemostasis. Definition of major bleeding in clinical investigations of antihemostatic medicinal products in non-surgical patients. J Thromb Haemost 2005;3(04):692-694

49 Held M, Grün M, Holl R, et al. Cardiopulmonary exercise testing to detect chronic thromboembolic pulmonary hypertension in patients with normal echocardiography. Respiration 2014;87 (05):379-387

50 Klok FA, Ageno W, Barco S, et al; PEITHO-2 Investigators. Dabigatran after short heparin anticoagulation for acute intermediaterisk pulmonary embolism: rationale and design of the single-arm PEITHO-2 study. Thromb Haemost 2017;117(12):2425-2434 